\title{
COLECCIONISMO E CULTURA LIBRARIA NA IDADE MODERNA Concha Varela-Orol
}

\author{
Universidade da Coruña
}

DOI: $10.17075 /$ cbfc. 2020.004 

Ninguén dubida hoxe que o invento da imprenta significou unha revolución quizais só comparable ás actuais tecnoloxías da información e a comunicación. O libro impreso supuxo unha penetración do texto escrito como nunca existira, por máis que os seus inicios fosen lentos e por máis que durante séculos parte da comunicación, incluída a científica, seguira a desenvolverse en grande parte mediante textos manuscritos, moi especialmente cartas, informes, etc. Pero os libros impresos, dende comezos da Idade Moderna, comezaron a formar parte da paisaxe das universidades, das institucións eclesiásticas e das bibliotecas particulares dos sectores máis favorecidos socialmente, aínda que fose en moi pequenas cantidades. Non hai que esquecer que a facilidade de aprendizaxe da lectura se viu favorecida polo feito da regularidade da letra impresa fronte á manuscrita, e así os textos impresos penetraron en capas máis populares, especialmente a través da impresión e venda de pregos soltos.

O libro impreso comezará, pouco a pouco, a ir desenvolvendo un novo negocio non moi distinto ó principio do dos manuscritos, de cuxo mercado procedían moitos dos primeiros impresores. Vendendo primeiro localmente, no local da imprenta ou noutros da localidade, a produción mecánica obrigaba a estender as vendas noutros territorios (Geldner 1998: 191-192). Así o negocio chegará a alcanzar dimensións internacionais, e acabará converténdose no "comercio da librería".

Tanto se desenvolveu o novo invento que o tópico do exceso de libros, un lugar común que se repite dende a antigüidade, se retoma no século Xvi. Comezan a aparecer os "malos libros" de que fala Lutero, e logo os libros que non deixan de ocasionar libros sobre os libros, unha literatura secundaria que non está feita más que por escolios, notas e conxecturas. Esta era, polo menos, a opinión do humanista e filólogo holandés Erycius Puteanus (Chatelain 2008). Non debía estar lonxe desta opinión o posuidor, lector ou bibliotecario que deixou unha nota sobre unha folla de garda dun impreso da Universidade de Santiago: "Tanto libro, tanto libro, tanto dinero gastado". 
Esta percibida abundancia de libros acabará desenvolvéndose no século XVII nun campo de saber autónomo, a res libraria, bibliografía e biblioteconomía, nos inicios dos estudos da historia da imprenta e nos intentos de categorizar e clasificar os libros, formando parte dos esforzos da sistematización do cońecemento, que se coñecerá co nome de historia literaria no século XviII, pero que é posible rastrexar dende o século xvi coa publicación da Bibliotheca universalis de Conrad Gesner (Miert 2016: 213).

Neste texto, a pesar do seu título tan xenérico, vou fixarme só en dous aspectos da denominada República das Letras: os libreiros e a súa capacidade de mobilizar libros por toda Europa, e as coleccións, privadas e institucionais, no seu papel na construción do cońecemento e a identidade. Intentarei facer esta exposición acompañada dalgunhas notas sobre o libro e as bibliotecas en Galicia e dos escritos de Martín Sarmiento, que tan ben coñeceu esta República literaria.

\section{O MERCADO INTERNACIONAL E A PUBLICIDADE DO LIBRO}

O grupo de comerciantes que chamamos libreiros estaba constituído dende o nacemento da imprenta por axentes diversos, que con frecuencia executaban distintas funcións. O termo aplicábase ós impresores, editores, libreiros no sentido actual do termo, encadernadores e mercadores de todo tipo, e que podían desenvolver unha ou varias destas actividades. Algunhas delas, nun número non desprezable de casos, foron desenvolvidas polos autores, que financiaban total ou parcialmente a edición, e tamén vendían libros nas súas casas.

Unha das máis importantes fontes que tiveron para coñecer os libros os homes e mulleres da Idade Moderna, e que nós temos para estudar a cultura libraria, é a publicidade dos libros. Dado que estes foron dos primeiros produtos fabricados en serie, dende moi pronto se buscaron formas de distribución e de publicidade. Xa no período incunable cońecemos anuncios con pequenas listas de libros, unha forma de publicidade xa cońecida en Roma (Coppens / Nuovo 2018). A distribución dos libros a distancia era realizada por axentes ambulantes que facían longas viaxes e os expoñían en fondas ou na casa dalgún comerciante, colocando anuncios dos libros nas portas das igrexas e lugares similares, soporte tamén dos edictos de prohibición da Inquisición, que non deixaron de contribuír á publicidade dos libros que condenaban. Os axentes ambulantes abastecían, ade- 
mais, os almacéns de que dispoñían os grandes impresores en distintas cidades, convertendo moi pronto este comercio en internacional (Geldner 2008: 195).

No tránsito do século XV ó XVI aparecen os primeiros antecedentes dos catálogos de librería, editados por Aldo Manucio en Italia. No primeiro deles o impresor italiano, xunto á descrición dos libros, engade o prezo, un dato que elimina nos posteriores posiblemente en consonancia cun mercado que xa superaba o ámbito local e que esixía modificar os prezos en función dos gastos de transporte, ou polos descontos que había de facer a outros libreiros (Coppens / Nuovo 2018). Malia estes antecedentes, podemos dicir que é no século XVI cando teñen lugar dous feitos de singular importancia para a historia da comercialización dos libros: a aparición dos primeiros catálogos de libreiros con forma de libros e as poxas de libros.

A medida que se produce primeiro unha deslocalización das vendas e logo unha internacionalización do mercado libreiro, os catálogos fanse máis abundantes nos grandes centros de produción. De especial importancia foron os da Feira internacional de Frankfurt, ó principio, en 1564, para os fondos do seu editor, o libreiro de Ausburgo Georg Willer, e a partir de 1573 para o conxunto de libros da feira. Grandes impresores como Robert Étienne tamén imprimiron catálogos dos seus libros. Os catálogos de Aldo e Étienne correspondían ós fondos impresos por eles, pero o catálogo que acabará xeneralizándose na Idade Moderna entre os libreiros ou os impresores/libreiros é o do fondo da súa librería, cos libros propios e cos doutros impresores, ademais de libros de segunda man. Incluían libros editados en distintos países, e frecuentemente datados dende o comezo da imprenta. Estes catálogos distribuíanse separadamente, polo propio libreiro e a súa rede comercial de librerías, pero encontrámolos tamén inseridos nos libros que editaban.

As poxas, como unha nova forma de comercialización dos libros, inícianse nas almoedas, das que falaremos posteriormente. Se ben a combinación de poxa e catálogo xa se cońece no século XVI en Leiden (Lechner 1991), nos séculos XVII e XVIII a combinación de ambos constitúe unha forma de revitalizar o comercio libreiro, fundamentalmente en Holanda e máis tarde en París, vivificado tamén pola súa especialización en libros antigos e raros. A expresión libro raro é usada xa en 1609 no título dun catálogo de venda de Luis Elzevier. Tamén en Francia se encontra no século XVII o uso do termo en catálogos do libreiro Thomas Jolly, datados ó redor de 1655 . Os libros destas poxas procedían dunha ou varias 
bibliotecas privadas vendidas polos herdeiros á morte do coleccionista, ou ben en vida para financiarse ou porque desconfiaban dos seus herdeiros, ás veces incluíndo tamén fondos da librería. Os catálogos impresos destas poxas alcanzaron unha circulación internacional, e foron a fonte da que se nutriría o coleccionismo de toda Europa. Incluían libros editados en distintos países, e frecuentemente datados dende o comezo da imprenta. As poxas celebrábanse en diferentes lugares, na casa do defunto propietario dos libros, especialmente cando se trataba dunha biblioteca copiosa, na tenda do libreiro ou en lugares públicos. A súa duración era variable en función do número de libros ofertados, nun só día ou en ata máis de vinte, aínda que a miúdo os catálogos só indican o día de comezo "e seguintes". En ocasións era posible examinar os libros nos días anteriores. O novo sistema de venda supoñía unha nova forma de fixación colectiva do prezo dos libros, que tamén fóra das poxas eran negociados entre comprador e libreiro en moitas ocasións. A mostra témola nunha carta de Ignacio de Heredia sobre a compra do conde de Aranda nunha almoeda parisina: "un libro que le costó 27 pesetas, lo compré yo en la misma librería pasados dos días por 3” (Pradells Nadal 2000: 187).

Certamente estamos a referirnos a catálogos de grandes libreiros con mercado internacional. Temos constancia da chegada a Galicia dalgúns destes catálogos, presentes hoxe nalgunhas bibliotecas da nosa comunidade. Os que nós coñecemos son todos do século xviII. A Biblioteca Universitaria de Santiago posúe catálogos de libreiros internacionais, tanto de fondo da librería como de poxas. Algúns figuran nos seus fondos a finais do século xviıI, como o da poxa de 1743 dos libreiros de Amsterdam Salomon Schouten e Pierre Mortier, a Bibliotheca Selectissima formada por uns 18.000 libros, entre eles algúns españois e portugueses.

Exemplares destes catálogos circulaban xa entre os eruditos españois do século Xvi, como Juan Páez de Castro e Jerónimo Zurita (Domingo Malvadi 2011: 358-369). No século XVIII chegaban directamente ós coleccionistas, entre eles Mayans e Sarmiento. Este último afirma que os catálogos dos libreiros europeos eran tamén obxecto de venda, xa que "se pueden hallar en muchas partes, y aún comprarse a moderado precio" (Sarmiento 1750-1751: 53). Os catálogos das grandes coleccións seguen comercializándose anos despois da poxa, pero a prezos elevados, como escribe Ignacio de Heredia a Roda en 1776: "Tengo en mi poder 
[...] los dos Cathalogos del Abbé de Rothelin, y Mr. De Bore [...]; pero tan caros [...] por lo que no me he resuelto a comprarlos hasta informarle" (Pradells Nadal 2000: 187). O primeiro era do ano 1746; o segundo de 1753.

A librería internacional desenvolveu no século xvir outras formas de publicidade, sobre todo para os libros dirixidos a un público erudito. Unha delas foi o prospectus, un texto impreso que daba a coñecer o interese da obra, o seu método, forma de presentación, etc. No século seguinte o prospectus combínase cun novo sistema de financiamento da edición, a subscrición, na que os lectores adiantaban en parte o pago da obra, obtendo a cambio un desconto, pero que servía tamén para crear contactos. Estas subscricións ás veces xestionábanse mediante redes de libreiros ou en librerías locais. As modalidades desta fórmula chegan a incorporar o que hoxe coñecemos como crowd content, ó pedir ós eruditos que acheguen información sobre o tema co fin de mellorar o contido da obra. Sirva de exemplo o anuncio publicado na Gaceta en 1734 do Diccionario histórico de Moreri, traducido ó español por José de Miravel y Casadevante, onde os libreiros Tournes de Lyon piden información de España, Portugal e Indias: "con este motivo se suplica a los Eruditos contribuyan al Author con las noticias, ò curiosidades, que puedan ilustrar tan gran Obra”. A subscrición foi utilizada con frecuencia para os libros de antigüidades e historia natural (Yale 2016: 17), e será o sistema de venda que adoiten ter as publicacións periódicas. Prospectus e subscrición publicitan o libro con anterioridade á súa impresión, o que facilitará a súa rápida aparición noutra forma de publicación, as publicacións periódicas.

A partir do século Xvir contamos tamén coas novas de libros nas recentemente nacidas publicacións periódicas. En 1665 iniciase en París a publicación do Journal des Çsavants, cuxo primeiro número contén esencialmente a descrición de libros aparecidos o ano anterior. Este tipo de publicacións, que demostran a eficiencia á que ten chegado a distribución do mercado libreiro, consolidan, así mesmo, a esfera pública e unha República literaria internacional.

En España o inicio destas publicacións será máis tardía, pero a prensa oficial, a Gazeta de Madrid e o Mercurio histórico y politico, inclúen anuncios de libros espańois e estranxeiros, onde se indican os lugares en que se venden en distintas cidades. Noutras ocasións, a prensa, como o Correo literario de la Europa (1781-1787) e o Correo mercantil de España y sus Indias (1792-1808), inclúe extractos e novas de libros dos libreiros estranxeiros que indican con frecuencia 
o seu prezo e o enderezo da libreiro/editor de París, Londres, etc. onde están á venda. Estes anuncios de libros deberon ter considerable éxito, xa que o Correo de Madrid en 1787 repite nalgúns números os anuncios do número anterior, segundo confesa o seu editor pola demanda dos lectores, e acaba anunciando a publicación mensual dun catálogo con todos os libros do mes.

Na década de 1780 xorden publicacións máis especializadas, como o Memorial literario instructivo y curioso de la Corte de Madrid (1784), que inclúe, entre outras novas, anuncios de libros, pero tamén anuncios da publicidade dos libros, por exemplo dos prospectus de libros editados fóra e que se traducen ó español. Ó ano seguinte nace tamén a Biblioteca periódica anual para la utilidad de los libreros y literatos, que testemuña a falta deste tipo de publicacións en España, e pide a colaboración dos "autores de provincias", cuxas obras son aínda máis descońecidas, ao tempo que nos informa de que seguían existindo carteis para publicitar os libros.

Os libreiros con mercado internacional visitan tamén ós libreiros que venden os seus libros en España, coa finalidade de facer negocios e distribuír os seus catálogos e novidades. Estas viaxes son aproveitadas para realizar contactos persoais cos coleccionistas, como nos testemuñan Sarmiento e Mayans. Nestas visitas os libreiros buscaban tamén orixinais españois con vista á súa edición, e, a través dos espańois, contactos con eruditos doutros países, como ben testemuña a abundante correspondencia conservada de Mayans. Destas relacións derivaban así mesmo envíos directos de libros, como indica Sarmiento en 1751 respecto ó libreiro italiano Leonardo Venturini: "El gigantón Venturini me escribió desde Milán [...]. Me remite seis tomos en folio de las Homilias de San Carlos Borromeo [...]; pero les pone el precio según la estatura de su cuerpo; y yo regulo los libros según otra estatura" (Sarmiento 1995: 67).

Seguramente as viaxes dos libreiros servían tamén para o intercambio e adquisición de libros do país visitado. Sarmiento nas Reflexiones literarias láiase dos emisarios que recollen libros por España para envialos fóra. Chama a atención os numerosos libros impresos en España nos séculos XVI e XVII que encontramos nun Catalogo de libros españoles dos libreiros lyoneses Deville.

Non esqueceron tampouco os libreiros ofertar os seus servizos ás bibliotecas. Os irmáns Deville diríxense á Biblioteca Universitaria de Santiago e envíanlle os seus catálogos, e tamén lle anuncian que na súa viaxe a Espańa pasarán por Com- 
postela. Entre os seus contactos debía figurar ademais o mosteiro de San Martiño Pinario, xa que se conserva na mesma biblioteca un libro de Jean-Baptiste Deville coa súa dedicatoria ó bieito Bernardo Ruiz.

\section{UN LECTOR DE CATÁLOGOS E BIBLIOGRAFÍAS NO SÉCULO XVIII}

Máis alá da súa primixenia finalidade comercial, os usos que os lectores facían dos catálogos de libreiros ou das poxas non se dirixían só á compra de libros. A súa lectura ía con frecuencia acompañada con anotacións en determinados libros, e nos catálogos de poxas indicábanse á man os prezos de adxudicación, como mostran moitos exemplares conservados en Europa. Eran tamén incluídos dentro das coleccións librarias, e frecuentemente asinados polos seus posuidores.

Vexamos como se servía deles Martín Sarmiento, quen nos deixou nos seus escritos varias relacións de libros seleccionados a partir de catálogos de librería. Ningún destes catálogos figura no índice da biblioteca de Sarmiento. Posiblemente as seleccións que conservamos fosen feitas sobre exemplares emprestados, como ocorreu con outras lecturas súas, razón pola cal foron lidos coa pluma na man, en lugar de anotados no propio catálogo. Participarían así da lectura erudita, destinada a posteriores usos, e analizada no caso dos cadernos de lugares comúns por Castillo Gómez (2016: 64).

$\mathrm{Na}$ orde en que aparecen estes extractos na Colección Medinasidonia baixo o título Precios de algunos libros, según los diferentes Catálogos que he visto impresos... (Sarmiento 1730-175-?), a primeira selección está realizada sobre un catálogo do libreiro veneciano Giovanni Battista Albrizzi. Este impresor, editor e libreiro poñía á venda libros propios e doutros moitos editores internacionais, como mostra a selección de Sarmiento, composta por libros editados en Italia, Francia, Alemaña e os Países Baixos nos séculos XVI, XVII e XvıII, entre eles a Biblia Regia de Arias Montano. Descoñecemos sobre que catálogo concreto do libreiro traballou Sarmiento e tamén o ano en que fixo esta selección, pero ten que ser posterior a 1734, xa que os libros máis recentes están editados en 1735. A selección sarmentina abarca 85 títulos e 454 volumes, ordenados alfabeticamente, posiblemente seguindo a orde do catálogo do libreiro, que edita así outros catálogos posterio- 
res. Anota tamén os prezos de cada libro, que sumaban 13.948 libras venecianas, equivalentes aproximadamente a 377 dobróns.

A segunda selección corresponde á revisión realizada por Sarmiento sobre un catálogo de Adrian Motjens, libreiro da Haia. A casa de edición Moetjens comezara no século XVII con Adriaen (I) Moetjens, e xogou dende os inicios un importante papel no comercio internacional de libros. No século xviıI tiña un sistema de venda por subscrición que xestionaba a través de libreiros de Reino Unido, Francia, Alemaña, Italia, Portugal e España. Os seus catálogos foron apreciados polos bibliógrafos de libros raros como Johannes Vogt e David Clément. O extractado por Sarmiento foi publicado baixo o título Bibliotheca exquisitissima, e corresponde a unha poxa de 1732. Está formado por unhas 12.000 entradas de manuscritos e impresos dos séculos XV a XviII, aínda que cun número maior de títulos, xa que incluía libros facticios. Moetjens numeraba cada un dos rexistros de libros e dividía os fondos en función do formato, iniciando unha nova numeración en cada formato. Sarmiento selecciona aquí 560 libros, prestando especial atención ós libros españois de historia e belas letras. Pero modificou o criterio de ordenación do catálogo, dividíndoos por clases e dentro de cada unha por formatos. Como o texto que conservamos é unha copia da Colección Medinasidonia, non podemos observar se empregou esta mesma orde na súa lectura a partir de carencias ou sobras de espazo no papel, pero, en todo caso, realizou unha reordenación do catálogo cun criterio atento ó seu contido e máis práctico para posteriores consultas. Aínda que seleccionou na maioría dos casos libros que Moetjens cualificara con algunha marca de rareza, non sempre seguiu o criterio do libreiro, incluíndo libros que non a tiñan ou modificando o grao de rareza. Sarmiento mostra así ter un bo cońecemento de moitos dos libros en venda, e o seu propio criterio respecto á súa rareza en España.

Podemos preguntarnos agora cal é o obxecto da revisión atenta dos catálogos e da redacción das escolmas sarmentinas. O número de libros que selecciona é demasiado voluminoso e custoso para ser obxecto dunha compra conxunta. Ademais, no caso do catálogo de Moetjens, nos exemplares facticios ás veces só selecciona un título dos distintos que compoñían o volume, o que indica claramente que non era a súa idea adquirir estes exemplares na poxa. Máis ben parece usar os catálogos como un instrumento de formación, apropiándose así dunha 
cultura libresca. Dende logo que tamén estes extractos lle permitirían no futuro facer algunhas compras para a súa importante biblioteca.

O uso que realizou Sarmiento sobre os catálogos de librería é igual ó que fixo sobre algúns tomos dunha bibliografía de libros raros alemá, a Bibliotheca curieuse de David Clément, tamén extractada polo bieito. Aínda que nos apuntamentos desta obra inicia o texto sinalando que os fai para identificar os libros raros da súa biblioteca, a realidade é que algúns dos anotados non os posuíu ou posuíunos en edicións distintas, o que parece sinalar maior atención ó texto que á rareza da edición.

Moi similar sería a lectura que faría sobre os catálogos publicados das grandes bibliotecas (Real de París, Oxford, etc.) e as bibliografías que figuran no catálogo da súa biblioteca, aínda que neste caso non necesitase facer apuntamentos, fóra dos posibles no corpo da obra. Neste sentido, os catálogos dos libreiros superaban a súa primeira finalidade, a venda de libros, para converterse en obras de coñecemento bibliográfico, ó igual que os catálogos de bibliotecas, as bibliografías e as publicacións académicas, das que Sarmiento posuía importantes e numerosas coleccións (Journal des Çsavants, Acta eruditorum, Philosophical Transactions, Mémoires de Trévoux, etc.). Nalgunhas destas obras debeu coñecer Sarmiento a Locke, un autor non presente na súa biblioteca, pero cuxa influencia sobre Sarmiento ten sido sinalada (Costa Rico 1997: II, 245-300).

Coa pluma na man debía acudir Sarmiento tamén ás librerías. Nas Memorias para la historia de la poesía (1775: 339) déixanos testemuño de ter consultado había anos un manuscrito do século xv de Calila e Dimna na casa dun libreiro que puña á venda algúns manuscritos que pertenceran a Manuel Pantoja e que despois serían vendidos a Portugal. Pois ben, Sarmiento transcribe literalmente o título, describe as ilustracións, e anota que a subscrición do manuscrito é de 1416, o que implica que na librería tomara as correspondentes notas.

Nos seus apuntamentos dos catálogos e das visitas a librerías Sarmiento testemuña o desexo de apropiación dun capital intelectual, difícil de adquirir por outras vías, e do que non deixa de facer uso noutros escritos. Un capital que empregará na década de 1740, nas Reflexiones literarias e no Catálogo de algunos libros curiosos y selectos, repetindo as anotacións tomadas no catálogo de Albrizzi das reimpresións venecianas dos Bolandos, Papebroquios, Grevios e Gronovios. 


\section{OS LIBREIROS LOCAIS}

Moi distinto ó comercio internacional é o caso dos libreiros locais da Idade Moderna, aínda que algúns sevillanos tiveron intereses comerciais transatlánticos. Ata o século XVIII coñecemos poucos catálogos de libreiros españois. De finais do século XVI é un do libreiro italiano asentado en Madrid Simone Vassalini (Rueda Ramírez 2018); do Xvir algúns sevillanos do libreiro Diego Crancer e do impresor López de Haro (Rueda Ramírez 2012), ou os madrileños de Gabriel León (Martínez Pereira 2016). Con frecuencia as existencias dos libreiros só poden coñecerse a través de inventarios post-mortem, por mor de vendas, cartas de dote, etc., ou dos realizados con motivo das visitas inquisitoriais, que nunca deixaron de ter os libros no seu punto de mira. Algúns destes inventarios foron estudados no caso galego por Juan Eloy Gelabert (1982), Ofelia Rey Castelao (2003) e Benito Rial Costas $(2007,2013)$, entre outros.

Adoita sinalarse a debilidade da produción de libros en Galicia, aínda a falta dunha bibliografía retrospectiva completa, que hai que enmarcar na debilidade da produción libraria en toda España. Por máis que na etapa incunable a imprenta se estableceu en moitos lugares, foi incapaz de manterse neles, e acabou concentrándose nas cidades que tiñan unha poboación suficiente para sostela (Wilkinson 2012: 497). A crise económica da segunda metade do século xvi tivo un forte impacto sobre a produción de libros. Sirva de exemplo que unha cidade como Sevilla, cun importante mercado americano, ve caer a impresión de libros neste período, e prima a importación sobre a produción propia, o que supuxo que esta se especializase en pregos soltos (Maillard Álvarez / Rueda Ramírez, 2008), os denominados entón "papeis", de grande éxito dada a súa abundante presenza nos inventarios de libreiros españois. Con razón os impresores lioneses do século Xvi, como Guillaume Rouillé, facían referencia nas cartas ó lector ó seu papel na edición de libros españois: "de las quales [importantes edicións] gozan quasi todas las otras naciones (o por lo menos la mayor parte dellas) salvo la suya española” (apud Baras 1981: 6).

Así pois, no Antigo Réxime é clara a dependencia española do mercado libreiro dos Países Baixos, Francia e Italia, que souberon aproveitar as vías comerciais doutras mercadorías para introducir os seus libros no mercado español. Os propios impresores e os seus factores instaláronse en España, onde vendían os libros 
máis baratos que os das imprentas locais. Os que non o facían viaxaban con frecuencia aquí. Andando o tempo, tamén tiveron como obxectivo sacar de España libros valiosos, unha práctica da que Sarmiento acusa ós libreiros españois como intermediarios dos libreiros estranxeiros.

A librería compostelá, que funciona como distribuidora para o resto de Galicia, nutriuse no século Xvi primeiro nos importantes centros libreiros de Valladolid e Medina del Campo, onde tiñan representantes os grandes impresores de Venecia, Lyon e Amberes; logo tamén en Salamanca, e non se descoñecen adquisicións en Francia e Flandres. Procedentes das poxas ou de adquisicións a particulares, as librerías revendían tamén libros de segunda man. Na librería de Giraldo de Sol (Rial Costas 2007) algúns libros eran vellos, e no inventario de Alonso Díaz (Castro 1968) eran usados ou vellos sobre un 30\% dos libros.

As provisións das nosas librerías non parece que fosen menores que as doutras cidades españolas no século Xvi. O inventario de Giraldo de Sol en 1552 ten 784 rexistros e mais de 2500 volumes; en 1558 o de Agustín de Paz 1208 (Gelabert 1982: 173); en 1563 o de Beatriz Pacheco 571 rexistros e 1500 volumes (Rial Costas 2013), cifras similares ás de inventarios doutras cidades. Comparemos a oferta coa dalgunhas librerías sevillanas do século Xvi: tres delas posuían entre 100 e 300 libros, catro entre 700 e 1800 libros, e tres superaban os 3000 libros; só dúas, cuxos libreiros eran tamén editores, superaban con moito estas cifras, pero tratábase de produtores de libros con numerosos exemplares dos títulos editados por eles (Álvarez Márquez 2007: 254-280). Estes datos corresponden á populosa Sevilla, nun momento ademais en que posúe o monopolio do comercio americano.

Un aspecto menos estudado é a variedade de títulos e edicións que estas librerías posuían, ó que non son alleas as dificultades que presenta a redacción dos inventarios, onde non é sempre posible identificar as obras e distinguir con claridade a indicación de edicións duplicadas e títulos editados en varios volumes. Se puidésemos xeneralizar os datos obtidos no estudo da librería sevillana, diriamos que as librerías máis pequenas, en xeral, se limitaban a un exemplar de cada título; as medianas adoitaban ter varios exemplares, e as grandes librerías tiñan moitos exemplares de cada título, con frecuencia debido ás edicións feitas polos propios libreiros. Cantidade e variedade parecen ir en sentidos contrarios. Así, en 1629 o inventario do libreiro/editor madrileńo Miguel Martínez ten 5258 volu- 
mes correspondentes a soamente 85 rexistros (Dadson 1997), xa que algúns dos títulos contaban con máis de 1000 exemplares. Unha parte destes volumes correspondía a libros que editaba o libreiro, e é posible que nalgún caso actuase como distribuidor, como na Arte de Nebrija, editada a conta do Hospital General de Madrid. Ademais, seguramente intercambiaría títulos con outros editores, como era frecuente. Dous anos antes, en 1627, o inventario de Alonso Díaz das Penelas, libreiro compostelán que non parece que se dedicase nin á edición nin á impresión de libros, ten 427 rexistros na tenda, e 142 en caixóns procedentes dunha compra. Os rexistros corresponden na súa maioría a poucos exemplares, con algunhas excepcións como libros de pequeno formato de obras de gran difusión polo seu uso nas escolas, como os dísticos de Michael Verinus, dos que tiña máis de 900 exemplares, ou 244 cartillas. Un cotexo feito por nós sobre distintos inventarios de librería xa estudados indica que esta era unha situación bastante xeneralizada.

Xunto ós libreiros atopamos tamén os mercadores ambulantes de libros. Ademais das compras feitas en Castela por libreiros, coñecemos unha viaxe a Galicia, encargada pola libreira de Valladolid Ana Vélez, para vender libros en Santiago e noutras cidades galegas en 1595 (Rojo Vega 2013: 381-401). Se ben é certo que as vendas de libreiros ambulantes e outros mercadores, feirantes, etc. adoitaban ser pequenos impresos (coplas, sermóns, catecismos, cartillas, etc.), representativos da lectura popular, non parece que fosen os únicos que se vendían en pregos soltos. Esta forma de publicación empregouse tamén para despachar outros libros por pregos coa finalidade de abaratar a súa adquisición. É o caso do Teatro crítico de Feijoo, que a partir de 1765 se fraccionou en discursos polo alto custo da edición.

Ó lado destas vendas ambulantes, os libros e papeis comercializábanse na Idade Moderna en moi variados lugares, en tendas de todo tipo, como un impreso de Diego Antonio Cernadas de Castro dunha ofrenda funeral a Feijoo, da imprenta santiaguesa de Pedro Frayz, impreso en 1765, que "se hallarà en la Tienda de el Sillero, frente Hospitalillo, junto a las Huerfanas", o barrio libreiro compostelán por excelencia. Vendíanse na casa dos propios autores cando estes financian a edición; e vendíanos tamén os seus posuidores, como mostran os anuncios da Gaceta de Madrid.

Unha distribución non menosprezable, pero pouco estudada, é a realizada nas porterías dos mosteiros e conventos, que representa un 10\% dos libros anuncia- 
dos na Gaceta (Buigues 1998: 517). Ás veces correspondía a edicións feitas pola orde. Era na portería de San Martín de Madrid onde no século XviII se vendía o Teatro crítico de Feijoo, que segundo nos informa o seu editor Sarmiento tan grandes beneficios lle proporcionaría, xa que cada tomo tińa un custo de entre 8000 e 9000 reais. Imprimíronse 1500 exemplares, que se vendían a 12 reais cada un, o que implicaba un beneficio de polo menos 9000 reais en cada tomo. No mesmo sitio venderíase posteriormente a impresión da Historia de la poesía $y$ de los poetas españoles de Sarmiento. Como testemuñan algúns pés de imprenta e os anuncios da Gaceta, algúns destes conventos en Santiago de Compostela eran os de San Agostiño, San Domingos de Bonaval, A Nosa Señora da Cerca e San Francisco. Neste último vendíase en 1747 a Doctrina pueril "compuesta en lengua lemosina por el B. Raymundo Lulio, traducido en Lengua Española”, segundo informa a Gaceta de Madrid de 12 de decembro dese ano.

No século XviII Madrid presenta un mercado libreiro relativamente puxante. As publicacións periódicas conteñen novas de grande interese para coñecer os libros que chegaban a Galicia a través dos anuncios de libros e dos avisos para realizar a subscrición. Tamén son de interese para a realización dun censo de librerías galegas no século XviII. En 1729 algunhas edicións madrileñas podían adquirirse na librería de Bernabé de Quintana; en 1750 na de Juan Francisco de Ponte y Andrade, na rúa da Sillería; en 1758 na de Cayetano Vázquez e Gregorio Blanco, na Praza do Campo, as tres en Santiago; en 1799 na de Laine ou Layne en Ferrol, onde tamén era posible subscribirse á Gaceta ou ó Diario de Madrid. En 1787 as subscricións ó Memorial literario, instructivo y curioso de la Corte de Madrid podían facerse na librería coruñesa de Vicente Gutiérrez, que tamén se encargaba de facelas para América. En 1818 na librería de Cardesa ou Cardeza na Coruña era posible subscribirse ó Diario de Madrid ou á Continuación del Almacén de frutos literarios.

Nas librerías madrileńas nutriuse a Biblioteca Universitaria de Santiago nas últimas décadas do século XviII, especialmente nas de Antonio de Sancha e Bernardo Alverá, onde adquiriu cerca de dous mil volumes. A documentación destas compras deixa claro o papel dos libreiros na selección de libros, xa que as solicitudes do bibliotecario eran, en ocasións tan xenéricas como "colecciones varias de viajeros". Antonio de Sancha prestou outros servizos á Universidade, como a realización do índice da biblioteca de Felipe de Castro e o seu depósito en 
Madrid, e a valoración da biblioteca do bispo de Blois. A súa librería era unha das mellores de Madrid, e dela editou algúns catálogos, onde, ademais de seleccións de libros do seu fondo, encontramos unha relación das futuras publicacións nas súas prensas, estratexia que tiña unha finalidade similar ós prospectus, a publicidade antes da publicación.

O aprovisionamento de libros realizábase igualmente en librerías de Madrid a través de amigos e correspondentes. Sarmiento realizou o papel de provedor de libros para os bieitos de San Martińo Pinario, como indica a dedicatoria do exemplar da Universidade de Santiago do libro Epistolae Apologeticae... (1715) de Bernhard Pez a Bernardo Ruiz.

Os libreiros vendían tamén libros "a exame”, é dicir, ocupábanse de fornecer na residencia do comprador os libros que pensaban que eran do seu interese. Francisco Manuel de Mena indica en carta a Mayans en 1741: "ya tenía dados los Aparatos (entraron con unos libros griegos en la celda del P. Sarmiento a vistas y alli se quedaron)" (Mestre 1993: 480).

Por suposto, libros de segunda man vendíanse nas almoedas locais. Correspondían a propiedades dun ou varios posuídores, e eran taxados previamente, usualmente por un libreiro, conservándose inventarios cos prezos de adxudicación. Con frecuencia inclúen pequenas coleccións, nas que os libros se vendían título a título, e eran comprados por individuos do mesmo sector profesional que o defunto. Tamén se poñían á venda en lotes ou a colección no seu conxunto, mercados preferentemente por institucións e libreiros. Sarmiento deixounos testemuño da picaresca que estes últimos poñían en marcha nestas poxas de libros, cuxa valoración facían previamente, para logo mercalos eles mesmos, e finalmente vendelos multiplicando os prezos. Nas almoedas adquiriu libros a biblioteca da Universidade de Santiago, e tamén os vendeu polo mesmo sistema, como fixo en 1776 cos libros duplicados procedentes dos Colexios dos xesuítas, do que conservamos o inventario, no que se indican autores, títulos, adxudicatarios e prezo en que se venderon, aínda que non falten indicacións xenéricas, tales como "once libritos viejos", e que tampouco falten algúns nomes de autores e compradores, os primeiros "por ser de poca consideración", os segundos por "no dar lugar la abundancia de compradores y confusión”, o que parece indicar o grande éxito da venda. 
Andando o tempo, algúns dos libreiros, ademais de vender libros, ofertaban outros servizos. Un ex libris dunha edición italiana de Filangieri de finais do século XviII, que debeu ingresar na Biblioteca Universitaria de Santiago máis tardiamente, infórmanos:

Esta y otras obras de todas clases antiguas y modernas se hallan de venta en la Coruña, librería de Pérez, calle Real número 84 al mismo precio que en Madrid.

En dicha librería se dan libros para leer en las casas á razon de 12 rs. al mes; y tambien hay un gran salon donde pueden léerse todos los periódicos de Madrid, y algunos franceses por la módica retribucion de 8 rs. Mensuales.

O libreiro corunés José María Pérez, aínda activo en 1850, aproveita o seu ex libris tanto para publicitar a venda de libros como os seus servizos de alugueiro e consulta. Aínda que os manuscritos medievais tamén se alugaban, e temos noticias de propietarios de libros impresos que tamén o facían a cambio dunha renda mensual (Lorenzo Pinar / Ferrero Ferrero 2004: 94), agora trátase dun libreiro que tenta desenvolver o seu negocio con actividades complementarias, o alugueiro de libros a domicilio e a lectura da prensa nas súas instalacións. $\mathrm{O}$ primeiro destes gabinetes de lectura, moitas veces chamados en Espańa gabinetes literarios, abriuse en Edimburgo en 1725. Na segunda metade do século XVIII e no xIx estendéronse por toda Europa, en Espańa especialmente no Trienio liberal, xeralmente ligados ós libreiros. Algúns destes gabinetes só ofertan a lectura da prensa, e é precisamente esta na que parece ter descansado o seu éxito, xunto coas obras de consulta, como as enciclopedias, ás que non todos podían acceder por causa dos seus prezos. A oferta de servizos destes gabinetes era variada, xa que nos seus anuncios na prensa madrileńa ofertan, ademais, venda dos periódicos, subscricións a libros e prensa estranxeiros, e ata billetes para a casa de baños. A comercialización dos servizos de lectura apóiase en distintas modalidades: lectura dos libros in situ, o seu alugueiro para a casa, o pagamento dunha cota ou dun depósito, o alugueiro de consulta de periódicos título a título, ou de toda a prensa dispońible, e ata o alugueiro da cadeira, sen que sexa posible permanecer de pé. Xunto ó seu papel de difusión da lectura, os gabinetes constituíron unha forma de ampliar o mercado libreiro e, como consecuencia, o negocio da librería. 


\section{O COLECCIONISMO DE COÑECEMENTO}

Destruír e construír son dous procesos inherentes ás bibliotecas na Idade Moderna, xa que, se algo as caracteriza, é o frecuente tráfico de libros que se produce entre elas, derivado en gran parte do comercio de libros de segunda man. Fronte á permanencia que caracterizara o coleccionismo medieval, as coleccións modernas parecen estar en continuo movemento. Este deambular de libros ten a súa apoteose en España ó finalizar a Idade Moderna, coa desamortización das bibliotecas dos mosteiros e conventos: os seus libros chegan a bibliotecas, privadas ou públicas, de Espańa e doutros moitos países europeos e dos Estados Unidos, cando non se destrúen ou se venden ó peso.

Nas bibliotecas o desprazamento dos libros ás veces proviña dos exemplares duplicados ou dos que non se consideraban necesarios, que se transferían a outra biblioteca. En ocasións facíanse trocos de libros duplicados por outros, e mesmo chegaban a mercarse libros coa finalidade de seren permutados, como confesa a Universidade de Santiago en 1796. Bibliotecas privadas de moi diverso tamańo, e tamén libros soltos, foron a integrarse en bibliotecas institucionais a través de doazóns e disposicións testamentarias. Almoedas e poxas disgregaban bibliotecas completas ou obras soltas, que pasaban a formar parte doutras bibliotecas. Encontramos todas as formas de adquisición, compra, doazón e troco, e todas as formas de venda, con inventarios e catálogos manuscritos ou impresos, ou coa exposición dos libros, vendas directas ou por encargo, bibliotecas completas, título a título ou por lotes.

Todas estas prácticas están documentadas nas bibliotecas privadas, moitas delas dende o século xvi. Sirvan de exemplo os esforzos nese século do humanista Juan Páez de Castro e do cronista Jerónimo Zurita, sempre atentos ás mortes dos eruditos con vistas a adquirir os seus libros, ou os do humanista italiano Fulvio Orsini, quen comprou exemplares de clásicos latinos da biblioteca de Pietro Bembo (Patińo Loira 2017: 189). No xvin testemuñan estas prácticas as compras feitas por Sarmiento de libros procedentes da biblioteca do Conde Duque, e os regalos e trocos que reflicte o seu catálogo. Modalidades similares encontramos nas bibliotecas dos mosteiros e das Universidades. Así se desfixo a biblioteca de Quevedo, que xa só en parte chegara ó mosteiro de San Martín de Madrid cos libros mercados á morte do duque de Medinaceli. O mosteiro vendeu os dupli- 
cados, e o importe obtido supúxolle moito máis do que pagara polo conxunto dos libros. A Biblioteca da Universidade de Santiago fai adquisicións en libreiros españois e estranxeiros, compra e vende en almoedas, recibe doazóns, e en 1796 troca ata 600 volumes por 580 .

O movemento dos libros, foran estes de bibliotecas privadas ou de bibliotecas monásticas, tamén se produce mediante os préstamos. Páez de Castro toma prestados libros de Diego Hurtado de Mendoza durante o Concilio de Trento (Domingo Malvadi 2011: 319). A biblioteca do mosteiro de Poio recibiu en 1729 libros en préstamo da Congregación de Valladolid para completar as súas coleccións. As bibliotecas dos mosteiros tamén deixaban libros a particulares, como ocorría no século XviII na de San Martiño Pinario. Os libros non sempre debían volver ós seus propietarios, e as reticencias son claras no caso de Poio, xa que os Capítulos da Congregación de Valladolid reiteran nos anos seguintes que se inventaríen para que sempre conste a súa propiedade. Tampouco nos préstamos entre particulares debían ser devoltos todos. Especial coidado respecto ó control dos préstamos mostra Sarmiento nas súas notas de lectura, onde indica os libros que ten emprestados, e que posúe na súa cela un catálogo dos libros que el emprestou. As reclamacións de libros tamén chegaban vía anuncios no Diario de Madrid, como este de 1798:

Si alguno tuviere libros prestados del difunto D. Miguel de Manuel, Bibliotecario [...] de los Reales Estudios [...], se servirá entregarlos [...] en la portería de San Isidro el Real, pues hacen falta para completar las obras. Igualmente si alguno le hubiese prestado algún libro, dando las señas se le entregará (18/9/1798).

Os frecuentes contactos epistolares entre os membros da República das Letras en boa parte servían para dar noticias sobre novos libros, ou para intercambialos, mandar libros propios, manuscritos ou impresos, e tamén obras mercadas por encargo. A correspondencia de Cornide con António Ribeiro dos Santos, conservada na Universidade de Santiago, exemplifica ben estes contactos ó redor dos libros. Se a isto engadimos no século xviII as innovacións do mercado libreiro, o intercambio de plantas e outros obxectos naturais, ou de transcricións de inscricións, etc., as viaxes literarias, sempre atentas ós libros e ás bibliotecas, e o nacemento de novas institucións científicas, podemos falar dun "comercio literario", 
e comezar a trazar un panorama da circulación do coñecemento na Idade Moderna, que sitúa as bibliotecas como parte dun coleccionismo do coñecemento.

\section{O COLECCIONISMO BIBLIÓFILO}

Como é coñecido, dende o século Xvi as prácticas coleccionistas expándense máis alá das igrexas e mosteiros, cun interese fundamentalmente dirixido ó mundo grego e romano, pero tamén ós estudos orientais, mediante as viaxes arqueolóxicas, cuxo punto de mira se vai desprazando das cuestións teolóxicas ás históricas e filolóxicas. Estas expedicións raras veces volvían sen manuscritos. Así con razón a Encyclopédie francesa consideraba que a erudición oriental comprendía tres ramas principais do cońecemento: a historia, incluíndo a historia das artes e as ciencias, as linguas e os libros. No século XVIII conflúen algúns factores que reforzarán este coleccionismo, como foron os descubrimentos de Pompeia e Herculano, a publicación de L'Antiquité expliquée de Montfaucon (1719-1724) e as viaxes literarias, que comezan a interesarse polas antigüidades nacionais. Sen dúbida, esta atención ás antigüidades nacionais non pode verse separadamente do desenvolvemento dunha historia nacional, na que as inscricións, as moedas, os monumentos, as esculturas e os textos escritos forman parte das fontes imprescindibles para a súa elaboración, como ben sinalaba Montfaucon.

Pero ó seu carón, xurdiu un coleccionismo distinto, moito máis especializado, que podemos chamar coleccionismo bibliófilo, aínda que o termo bibliofilia non aparece ata o século XIX, e nos dicionarios españois ata o século XX. A principios do século XVII unha nova tipoloxía bibliográfica comeza a aparecer nos catálogos da librería que poñían á venda bibliotecas particulares ou grandes coleccións de libros procedentes de distintas bibliotecas, e que se manifesta en cualificativos aplicados ós títulos dos catálogos ou a algúns libros dentro deles como rari, praestantissimi, exquissitimi, insigni, curiosi, sós ou combinando varios destes termos. Non cabe dúbida de que estas denominacións tiñan unha intención claramente comercial, xustificar un incremento nos prezos dos libros, pero sen dúbida serviron tamén para atribuír un valor simbólico sobre a nova clase de libros, os libros raros e curiosos. A mediados dese século esta clase de libros comeza a teorizarse, especialmente polos bibliógrafos, e convértese nunha auténtica categoría bibliográfica. Caracterizada con criterios distintos, tres elementos acaban 
delimitándoa: a escaseza de exemplares, a súa manufactura e a singularidade da temática. Libreiros e doutos contribuirán á creación de novos libros raros. Os primeiros, mediante tiradas dalgúns exemplares dos seus catálogos en gran papel de Holanda. Os segundos, imprimindo curtas tiradas, por exemplo dos catálogos das súas bibliotecas, que distribuían entre os seus amigos e non chegaron a comercializarse.

A razón da aparición dos libros antigos e raros foi relacionada polo investigador holandés Fontaine-Verwey (1963) coa aparición das novas ciencias no século XVII, hipótese que encontramos moito máis acaída que a simple atribución a unha moda promocionada polos propios libreiros. Perdido o seu interese informativo, estes libros manteńen o seu valor histórico como fontes para a historia do coñecemento, denominada entón historia literaria. A eles engádense libros con valores artísticos ou relacionados coa excepcionalidade da súa temática, da súa impresión, ou do escaso número de exemplares conservados. Todos eles comezan así a formar parte das antigüidades e as curiosidades, expresan o capital cultural de quen os posúe, e dalgunha forma a proxección dunha identidade persoal.

\section{O COLECCIONISMO DE IDENTIDADE}

Pero dende algún momento a mediados do século xvir os libros antigos e raros comezan a ser obxecto de interese por valores emotivos e simbólicos que remiten á historia e á cultura da nación, acompañando a construción das identidades nacionais. Comeza agora a creación do patrimonio bibliográfico, como mostra a historiadora francesa Fabienne Henryot (2012), que rastrexou o nacemento do carácter patrimonial dos manuscritos dende finais do século XvII nas comunidades relixiosas, especialmente entre os beneditinos.

Martín Sarmiento, que, como é ben cońecido, estivo moi influenciado polos maurinos, deixounos abundante información sobre o mundo do libro, e sobre todo ideas novidosas para a reforma do sector libreiro e as bibliotecas. Reuniu unha importantísima biblioteca con máis de 5500 volumes no catálogo que el mesmo redactou. Seguramente é o máis claro expoñente do coleccionismo de coñecemento, pero tamén da patrimonialización dos libros en Espańa. Xa nos referimos ó uso feito por el sobre o catálogo da poxa de Moetjens. Imos deternos agora neste catálogo. Nel as Belas Letras e a Historia constituían máis da metade dos 
cerca de 12.000 libros que ofertaba o libreiro, e eran as disciplinas que achegaban a porcentaxe máis alta de libros sinalados como raros. Destes libros, Sarmiento anota na súa selección máis do $89 \%$ dos libros raros españois de Historia e mais do $93 \%$ dos de Belas Letras. Noutras materias, como a teoloxía e a xurisprudencia, moito menos representadas no catálogo, selecciona o $100 \%$ dos raros espańois, e en ciencias o $81 \%$. Que nos din estes datos? En primeiro termo que eran as materias que pońen de relevo a lingua e a historia común as mellor representadas no catálogo do libreiro holandés, ademais das que proporcionaban maior porcentaxe ós rara, o que tamén resulta indicativo dos intereses bibliófilos que o libreiro supoñía en Europa, e Sarmiento, seleccionando principalmente libros españois, é unha boa mostra dese interese.

Conservamos tamén unha relación do beneditino baixo o título Libros raros en castellano, formado por 71 entradas de libros dos séculos XV ó XVIII, ás veces referencias xenéricas a un autor, un tema ou a un xénero. Sarmiento non limita a lista de libros a aqueles que son difíciles de atopar, senón que inclúe obras que cualifica de triviais noutros escritos, como o Nobiliario do Conde de Barcelos ou o Fuero Juzgo. En canto ás materias as Belas Letras e a Historia seguen a ser as máis representadas. Por outra parte, o interese filolóxico de Sarmiento non se reduce ós libros de Belas Letras, xa que "todo Libro Antiguo, es Libro de Lengua; pues las voces que no han quedado en uno, quedaron en otro" (Sarmiento 2008: 204). No Sistema de adornos (Sarmiento 2002b) subliña o papel de lugares de memoria que Sarmiento outorga ós libros, titulando a súa selección para enterrar no Palacio Real como "Memorias subterráneas". As súas palabras para referirse a estes libros van sempre cargadas de afectividade e simbolismo, memoria e emocións, compoñentes básicos da identidade colectiva que representa o patrimonio: "preciosos monumentos literarios", "libros propios y nacionales".

O concepto de patrimonio, indisociable dos procesos de formación identitaria en Europa (Thiesse 2010: 12), supón a necesidade de determinar que pezas forman ese patrimonio, a súa descrición, protección e a concepción de tales coleccións como bens públicos. Determinar o patrimonio é seleccionar e inventariar a herdanza da nación, idea na que Sarmiento insiste unha e outra vez. Nas Reflexiones literarias con vistas á protección das obras patrimoniais propón a elaboración e impresión dun catálogo que permita identificar as obras, impedindo a súa saída de España polos portos de terra e mar. No mesmo texto Sarmiento 
mostra o sentido de perda que lle supón o comercio de libros antigos e raros, "monumentos de literatura que yo quisiera que no saliesen fuera de la patria" (Sarmiento 2002a: 122-123).

Pero as súas propostas non rematan aquí: estes libros deben ser propiedades públicas e ser custodiados por institucións públicas. Así di que cando nos portos se confisquen estes libros sexan distribuídos polas bibliotecas públicas, con preferencia da Biblioteca Real, e, se alguén lle comenta que quere desfacerse dalgúns deles, remíteos á Biblioteca Real, outorgándolle deste xeito o papel de depósito nacional. En relación con esta idea do patrimonio público hai que enmarcar as abundantes doazóns feitas en toda Europa de coleccións privadas ás bibliotecas públicas, cando non foron directamente o xermolo da súa creación, como ocorreu en España coa do marqués de la Compuesta. O propio Sarmiento, como é cońecido, quería deixar a súa colección para abrir unha biblioteca pública en Pontevedra, o que, dende logo, non podía facer, pois á súa morte pasaba ó mosteiro de profesión.

Paralelamente á reconceptualización destes libros prodúcese unha relocalización. Cando Sarmiento propón a disposición do edificio para a Biblioteca Real, sinala que se deben conservar separadamente "las ediciones primitivas y raras de los autores famosos, $y$, en especial, las de letra gotiquilla de nuestros autores españoles, pues ya pasan de originales" (Sarmiento 2002a: 58). Esta separación encontrámola tamén nas coleccións particulares, onde constitúen gabinetes especiais. $\mathrm{O}$ anticuario catalán Jaume Pasqual posuía unha biblioteca, que, cando en 1808 Jaime Villanueva visita o mosteiro premonstratense de Bellpuig, está formada por un espazo que contén os libros, e dúas alcobas, unha cos códices e outra onde se atopan as moedas, medallas e obxectos de historia natural (Velasco González 2011: 52-54). Por poñer un exemplo dun galego en Madrid, aínda que do século XIx, lembremos que cando Parga y Puga realiza o seu testamento sinala: "dejo un Estante que está en mi Gabinete a la mano derecha, conforme se entra a la Alcoba, con todos los libros que contiene, de literatura antigua y moderna, a la Biblioteca de la Ciudad de Santiago". Estes libros tiñan tamén un papel lexitimador do nacionalismo español e da súa brillante cultura, fronte ó resto da súa biblioteca, dispersa hoxe en distintas institucións espańolas. A propia doazón será entendida en clave patriótica por Neira de Mosquera (1941: 353), que a sitúa na tradición dos fillos de Galicia "amamantados en el sentimiento del provincialismo". 
A mirada sobre os outros é tamén constitutiva dos procesos de creación da identidade propia. Sarmiento nunca deixou de estar atento ós "outros". Ó igual que estes libros antigos e raros representaban o estatus e a cultura dos coleccionistas, a súa presenza nas bibliotecas públicas era símbolo do poder e da cultura da nación. Tamén disto nos achega Sarmiento testemuño, ó comparar as coleccións de manuscritos arábigos da Biblioteca Real francesa cos da Biblioteca do Escorial, algo superiores en número nesta última: "Es corto el exceso, pero aun la igualdad sorprendera à muchos, y aun a los mismos Franceses, que suelen ponderar sus cosas, y siempre con preferencia” (Sarmiento 1750-1751: 54-55).

É aquí onde pensamos que hai que situar os Libros raros en castellano de Martín Sarmiento, unha relación, que, aínda que parca en datos bibliográficos, dános suficientes claves para a súa identificación, e cuxa finalidade é seleccionar o canon dos libros que representan a herdanza da nación española.

\section{CONSIDERACIÓNS FINAIS}

Durante a Idade Moderna os libreiros foron quen de imprimir a produción científica e cultural dende o mundo clásico ata a coetánea. Sostiveron unha considerable circulación de libros nacional e internacional, con estratexias de venda e publicidade que se van implantando por toda Europa sucesivamente ó longo deses séculos, e que aínda permanecen hoxe en día. Nos seus catálogos dannos non só noticias das obras impresas, coñecidas e non coñecidas hoxe, senón tamén dos sistemas de catalogación e clasificación dos libros, dos seus prezos, da colaboración entre distintos libreiros para abordar obras custosas, das redes de circulación dos libros en Europa, e ata da composición das bibliotecas de persoeiros no caso dos libros de anticuaria.

Ademais, crearon categorías de libros con fins moi diversos que acabarán orixinando distintos tipos de coleccións. Identificamos polo menos tres tipos de coleccionismo, ás veces concorrentes na mesma persoa. Un coleccionismo de coñecemento, presente nas bibliotecas monacais, institucionais e privadas. Del é unha boa mostra a biblioteca enciclopédica de Martín Sarmiento. No catálogo dos seus fondos é perceptible tamén, un coleccionismo bibliófilo, como cando indica que mercou obras duplicadas por seren raras. Os Libros raros en castellano, unha relación cuxa finalidade é identificar o canon dos libros que representan a 
herdanza da nación, son testemuña de que Sarmiento é así mesmo un exemplo de coleccionismo para a identidade.

Sobre todos estes coleccionismos construíuse en Europa o comercio da librería, do que se serven e se lamentan a un tempo os doutos, porque "presto se hallará [España] aún sin aquellos libros propios y nacionales que primitivamente se imprimieron en estos reinos, y de los cuales jamás se ha hecho reimpresión" (Sarmiento 2002a: 124-125). 


\section{REFERENCIAS BIBLIOGRÁFICAS}

Álvarez Márquez, María del Carmen (2007): La impresión y el comercio de libros en la Sevilla del Quinientos. Sevilla: Universidad, 2007.

Baras, Marie-Rose (1981): Les livres espagnols impremés à Lyon au seizième siècle. Memoire [...] sous la direction de Monsieur H.-J Martin et Monsieur C. Peligry. [S.l.]: [s.n.] <http://www.enssib.fr/bibliotheque-numerique/recherche?mots_cles=Baras\&lancer_la_recherche=oui> .

Buigues, Jean-Marc (1998): «Las lecturas más comunes de los españoles en el siglo XvıI», Bulletin Hispanique 100, 2, 515-530. <https://doi.org/10.3406/hispa.1998.4984>.

Castillo Gómez, Antonio (2016): Leer y oir leer. Ensayos sobre la lectura en los siglos de Oro. Madrid: Iberoamericana. <https://doi.org/10.31819/9783954878796>.

CAStro, Manuel (1968): «Inventario de una librería de Santiago a comienzos del siglo Xviı», Cuadernos de Estudios Gallegos 23, 313-335.

Chatelain, Jean-Marc (2008): «L'excès des livres et le savoir bibliographique», Littératures classiques 66, $143-160<$ https://doi.org/10.3917/licla.066.0143>.

Coppens, Christian / Angela Nuovo (2018): «Printed catalogues of booksellers as a source for the history of the book trade», JLIS.it 9, 2, 166-178 < https://doi.org/10.4403/jlis.it-12465>.

Costa Rico, Antón (1997): «A dimensión pedagóxica do Padre Sarmiento», en Congreso Internacional do Tricentenario de Fr. Martín Sarmiento (1695-1995). O Padre Sarmiento e o seu tempo. Vol. II. Santiago: Consello da Cultura Galega / Universidade de Santiago, 245-300.

Dadson, Trevor J. (1997): «La librería de Miguel Martínez (1629), librero y editor del primer tercio del siglo XVII», Bulletin Hispanique 99, 1, 41-71. <https://doi.org/10.3406/hispa.1997.4926>

Domingo Malvadi, Arantxa (2011): Bibliofilia humanista en tiempos de Felipe II. La biblioteca de Juan Páez de Castro. Salamanca / León: Universidad de Salamanca / Universidad de León.

Fontaine-Verwey, Herman de la (1963): «La bibliophilie aux Pays-Bas», en Deuxième Congrès International de Bibliophilie. Actes et Communications. París: s. n., 85-94.

Gelabert González, J. Eloy (1982): «Lectura y escritura en una ciudad provinciana del siglo xvi: Santiago de Compostela", Bulletin Hispanique 84, 3-4, 264-290. <https://doi.org/10.3406/hispa.1982.4474>.

GeLdner, Ferdinand (1998): Manual de incunables. Madrid: Arco Libros.

Henryot, Fabienne (2012): «Les réguliers et la patrimonialisation du manuscrit au xviII ${ }^{e}$ siècle», en Fabienne Henryot (ed.): L'historien face au manuscrit: Du parchemin à la bibliothèque numérique. Louvain: Presses Universitaires, 127-145.

LeCHNER, Jan (1991): «Autores españoles en bibliotecas holandesas 1550-1650», Bulletin Hispanique 93, 1, 221-237. <https://doi.org/10.3406/hispa.1991.4741>.

Lorenzo Pinar, Francisco Javier / Florián Ferrero Ferrero (2004): «Fuentes locales para el estudio del libro y de la lectura en Castilla en el siglo Xvir: problemas y perspectivas de trabajo», Revista de Historia de la Cultura Escrita 13, 45-62.

Maillard Álvarez, Natalia / Pedro Rueda Ramírez (2008): «Sevilla en el mercado tipográfico (s. XV-XviII): de papeles y relaciones», en Carmen Espejo (ed.): Relaciones de sucesos en la Biblioteca Universitaria de Sevilla: antes de que existiera la prensa. Sevilla: Biblioteca de la Universidad de Sevilla / Facultad de Comunicación de la Universidad de Sevilla, 13-25 <http://hdl.handle.net/10760/12593>. 
Martínez Pereira, Ana (2016): «Los catálogos del mercader de libros Gabriel de León (y otros catálogos del siglo XviI)", en Pedro José Rueda Ramírez / Lluís Agustí (eds.): La publicidad del libro en el mundo hispánico (siglos XVII-XX): los catálogos de venta de libreros y editores. Madrid: Calambur, 17-42.

Mestre, Antonio (ed.) (1993): Epistolario XII. Mayans y los libreros. Valencia: Ayuntamiento de Oliva.

Miert, Dirk van (2016): "A conceptual approach to library history. Towards a history of open science», Quaerendo 46, 205-221. <https://doi.org/10.1163/15700690-12341355>.

Neira de Mosquera, Antonio (1853): «Sobre una colección de libros», Semanario Pintoresco Español, 8-V-1853, 145-150.

Patiño Loira, Javier (2017): «Imagining public libraries in Sixteenth-Century Spain», Pacific Coast Philology 52, 2, 195-205.

Pradells Nadal, Jesús (2000): «Política, libros y polémicas culturales en la correspondencia extraoficial de Ignacio de Heredia con Manuel de Roda (1773-1781)», Revista de Historia Moderna 18, 125-222. $<$ https://doi.org/10.14198/RHM1999-2000.18.07>.

Rey Castelao, Ofelia (2003): Libros y lectura en Galicia. Siglos XVI-XIX. Santiago de Compostela: Xunta de Galicia.

Rial Costas, Benito (2007): Producción y comercio del libro en Santiago (1501-1553). Madrid: Calambur.

Rial Costas, Benito (2013): "The inventory of Beatriz Pacheco's bookshop (Santiago de Compostela, 1563)", en Malcolm Walsby / Natasha Constantinidou (eds.): Documenting the early modern book world: inventories and catalogues in manuscript and print. Leiden: Brill, 321-340. <https://doi. org/10.1163/9789004258907_014>.

Rojo Vega, Anastasio (2013): «From Europe to Finisterre: A caravan of books to Galicia (1595)», en Benito Rial Costas (ed.): Print culture an peripheries in Early Modern Europe: A contribution to the history of printing and the book trade in small European and Spanish cities. Leiden: Brill, 381-401. <https://doi. org/10.1163/9789004235755_018>.

Rueda Ramírez, Pedro (2012): «Libros venales. Los catálogos de venta de los libreros e impresores andaluces (siglos XVII-XVIII)", Estudios Humanisticos. Historia 11, 195-222 <https://doi.org/10.18002/ehh. v0i11.3166>.

Rueda Ramírez, Pedro (2018): «La venta de libros italianos en Madrid en tiempos de Felipe II: el catálogo de Simone Vassalini (1597)», JLIS.it 9, 2, 280-293 < https://doi.org/10.4403/jlis.it-12453>.

Sarmiento, Martín (1730-175?): Precios de algunos libros, según los diferentes Catálogos que he visto impresos de León, París, Ginebra, Holanda, Inglaterra, Venecia, etc. Museo de Pontevedra, Colección Medinasidonia, T. II, 525-570.

Sarmiento, Martín (1750-1751): Sobre los códices orientales de la Real Biblioteca del Escorial. Archivo General de la Fundación Casa Medinasidonia, Colección Medinasidonia, T. VI, 51-105.

Sarmiento, Martín (1775): Memorias para la historia de la Poesía y Poetas españoles. Madrid: Joachin Ibarra.

Sarmiento, Martín (1995): Cartas al Duque de Medinasidonia (1747-1770). Introducción y notas de José Santos Puerto. Ponferrada: Instituto de Estudios Bercianos.

Sarmiento, Martín (2002a): Reflexiones literarias para una Biblioteca Real (A referencia cultural da Ilustración española). Edición e estudo de José Santos Puerto. Santiago de Compostela: Consello da Cultura Galega.

Sarmiento, Martín (2002b): Sistema de adornos del Palacio Real de Madrid. Edición, introducción y notas de Joaquín Álvarez Barrientos y Concha Herrero Carretero. Madrid: Sociedad Estatal de Conmemoraciones Culturales. 
Sarmiento, Martín (2008): De historia natural y de todo género de erudición. Obra de 660 pliegos. Vol. IV. Santiago de Compostela / Madrid: Consello da Cultura Galega / Consejo Superior de Investigaciones Científicas.

Thiesse, Anne-Marie (2010): La creación de las identidades nacionales. Madrid: Ézaro.

Velasco González, Alberto (2011): Jaume Pasqual, anticuari i col-leccionista a la Catalunya de la Il-llustració. Lleida: Universitat.

WiLkinson, Alexander S. (2012): «Exploring the print world of Early Modern Iberia», Bulletin of Spanish Studies 89, 4, 491-506. <https://doi.org/10.1080/14753820.2012.684919>.

Yale, Elizabeth (2016): Sociable knowledge. Natural History and the nation in Early Modern Britain. Philadelphia: University of Pennsylvania Press. <https://doi.org/10.9783/9780812292251>. 
II. EDICIÓN DIXITAL

E CORPUS LINGÜíSTICOS 
